\title{
Anal Kaposi Sarcoma
}

National Cancer Institute

\section{Source}

National Cancer Institute. Anal Kaposi Sarcoma. NCI Thesaurus. Code C5602.

A Kaposi sarcoma arising from the anus. HIV-positive patients have an increased risk of developing Kaposi sarcoma in the perianal region. 